\title{
Relational Model between Parental Dental Belief and Formation of Dental Fear among Preschool Children in Indonesia
}

\author{
${ }^{1}$ Department of Paediatric Dentistry, Faculty of Dentistry, \\ Universitas Padjadjaran, Bandung, Indonesia \\ 2Faculty of Psychology, Universitas Padjadjaran, Bandung, \\ Indonesia
}

Arlette Suzy Setiawan ${ }^{1, \oplus}$ Lenny Kendhawati ${ }^{2}$ Hendriati Agustiani²

\begin{abstract}
Address for correspondence Arlette Suzy Setiawan, drg., Sp.KGA(K), M.Si, Department of Paediatric Dentistry, Faculty of Dentistry, Universitas Padjadjaran, Bandung, Indonesia (e-mail: arlette.puspa@fkg.unpad.ac.id).
\end{abstract}

Eur J Dent 2019;13:426-431

\begin{abstract}
Objective Parents' behavior and belief can strongly impact preschool children. Parents play an important role in the formation of dental fear. The aim of the research is to analyze parental dental belief model as a source of dental fear among preschool children.

Materials and Methods The research was undertaken at 15 kindergartens in Bandung City, Indonesia, which were chosen by means of multistage cluster random sampling. The participants of the research were parents and children aged 3 to 6 . The research involved analysis of quantitative data to assess the relational model between parental dental belief and the formation of dental fear among children. While parental dental belief was measured using the Dental Belief Scale, children's dental fear was measured using the Indonesian transadaptation of the Children's Fear Survey Schedule-Dental Subscale based on parents' report. The results were analyzed statistically by using structural equation modeling which is a combination of regression and factor analysis.

Keywords

Results The results indicate that the direct effect structural model of parental den-

- children tal belief significantly fit the formation of dental fear among children in Bandung

- dental belief $(t$-value $=2.41)$.

- dental fear

Conclusion The research concludes that parents' perception and behavior-the

- parents latter contributing more-correlate with the formation of dental fear among preschool children.
\end{abstract}

\section{Introduction}

Dental fear (DF) is an issue of important concern in dentistry. Epidemiological studies have shown that in the United States, the prevalence of DF ranges between 13.1 and 19.8\%, although gender difference is not reported. ${ }^{1}$ Concerning its impact, DF is unique in that it can result in a self-perpetuating cycle. ${ }^{2}$ In other words, fear of an object or situation related to a dental situation. Unaddressed DF may lead to increased dental care needs, a situation that can worsen dental, oral, and mental health as well as life quality in general. DF may evoke physical, cognitive, emotional, and behavioral responses in an individual. This is a frequently encountered problem in dental offices. ${ }^{3}$ Children who have a lower frequency of visits demonstrated higher DF scores. ${ }^{4}$

Parental behavior and belief affect children's behavior, including DF. ${ }^{5}$ Parents, especially mothers with DF, can significantly affect their children's behavior and cause DF in them. Generally, parents with high level of anxiety will likely show a negative behavior that may affect dental care success. ${ }^{6}$ 
Regardless of whether their children have DF, parents with DF tend to feel afraid and frequently ask questions about the treatment their children receive. ${ }^{5}$

Parenting styles provided an environmental framework for children's psychosocial growth and were assumed to shape children's behaviors. ${ }^{6}$ Due to the important role they play in the formation of children's behavior to dental treatment, parents must inform their children about what they should do while in a dental clinic. Children should be informed about the dentist who treats them and the situation that may occur during appointment. Parents should not tell about the terrible pain their children may feel. Honest information is necessary and exaggerated and emotional tone is to be avoided. ${ }^{5}$

Parental dental belief (DB) includes parents' knowledge about the risk of DF formation, consequences of having children with DF, advantages of DF prevention, and problems of DF prevention. Parents' knowledge about these matters is indicated by their readiness to act. How they act reflects their efficacy, DF prevention strategy, and awareness of their position in the formation of DF in their children. The aim of the research is to analyze parental DB model as a source of the formation of DF among preschool children. It was hypothesized that there is a relationship between DB and parents' perceptions about DF in preschool children.

\section{Method}

\section{Sample Size Calculation}

This research has been ethically approved by Universitas Padjadjaran's Ethics and Research Committee. Total sample size was calculated to determine whether a correlation coefficient differs from zero. Threshold probability for rejecting the null hypothesis $(\alpha)$ is 0.500 , probability of failing to reject the null hypothesis under the alternative hypothesis $(\beta)$ is 0.150 , and the expected correlation coefficient $(r)$ is $0.150,{ }^{7}$ a minimum of 396 subjects are needed to detect an effect size of 0.5 .

\section{Participant Recruitment}

A list of kindergarten schools was retrieved from the official data at the Education Bureau Office, Bandung City, Indonesia. The multistage cluster random sampling technique is processed as follows, each of the five regions of Bandung City is chosen, three districts randomly, and from each district, one school is chosen randomly. So, among a total of 479 schools, 15 were randomly selected and approached. The research subjects were parents (mothers) and preschool children (3-6 years old) at several kindergartens in Bandung. Each parent had to fill in an informed consent form and research questionnaires.

\section{Questionnaires}

Each participating parent was asked to complete a set of two questionnaires. The questionnaires were distributed via class teachers and were completed by the participants at home on a self-administered basis. Clear instructions were given to avoid confusion. All questionnaires were completed anonymously. Each participating parent was identified with a code and their names were not disclosed.
The first questionnaire is based on the Children's Fear Survey Schedule-Dental Subscale (CFSS-DS). ${ }^{8,9}$ The scale is to measure the parental perception on their child's DF. The questionnaire consisted of 15 questions with 5 Likert scales from "No Fear" (score 1) to "Very scared" (score 5). The total score ranged from 15 to 75 , with DF criteria being a score of 30 and above. The scale has underwent a series of transadaptation processes and tests, which yielded a Chronbach's alpha value of $0.956 .^{10}$

The second questionnaire Dental Belief Scale (DBS) was developed based on the adoption of Health Belief Model (HBM) and Social Learning Theory. ${ }^{11,12}$ DBS is the level of parental beliefs about matters relating to dental health and children's DF. It consists of seven constructs; perceived susceptibility, perceived severity, perceived benefit, perceived barrier, cues to action, self-efficacy, and locus of control. The answer to each questionnaire item is scored based on the 5-point Likert scale. Answers range from "Very Likely" to "Very Unlikely." The scale was further developed by using a descriptive method. Reliability and validity of DBS was measured on the scale followed by SPSS and LISREL analysis. Data showed that DBS has a high reliability of 0.799 , with the reliability on every subscale ranged at 0.780 to $0.803 .^{13}$

This quantitative research used a descriptive correlational design and a cross-sectional approach. ${ }^{14,15}$ The research involved quantitative data gathering and analysis to assess the correlation between parental DB and the formation of DF in preschool children.

\section{Statistical Analysis}

Research questions about how the model of the relationship of DBs with the perception of parents about the formation of DF in preschool age children is answered through model analysis with structural equation modeling (SEM) ${ }^{16}$

\section{Results}

The total score of parental DB varied from 69 to 281 (average total DB score for young adults was $173.6 \pm 31.1$ and for middle-aged adults was $170.5 \pm 34.9$ ). DB among adults can be categorized into the following dimension categories: perceived susceptibility, perceived severity, perceived benefit, perceived barrier, cues of action, self-efficacy, and locus of control. - Fig. 1 shows that in all dimensions, most respondents were in the moderate category. The minority chose the high category, except in the locus of control dimension.

DF among children was measured from their parents' perception of the fear the children felt. The children's total DF scores were between 15 and 63, ranging from non-DF to severe DF categories. - Fig. $\mathbf{2}$ shows that overall, parents' perception of their children's DF is under the light DF category $(n=286 ; 63.5 \%)$.

- Table 1 shows the SEM analysis result. From structural modeling, a value of $\chi^{2} / \mathrm{df}=59.86 / 25$ and a probability of 0.00011 show good results because of the comparison of chisquare with degrees of freedom (df) less than 3 (2.394) and root mean square error of approximation of 0.056 . In addition, the values of goodness-of-fit index $=0.98$ and comparative fit 
index $=0.99$ were obtained at $>0.90$. Thus, the overall structural model is declared fit and there is no need to modify the model. The modeling results can be seen in - Fig. 3 .

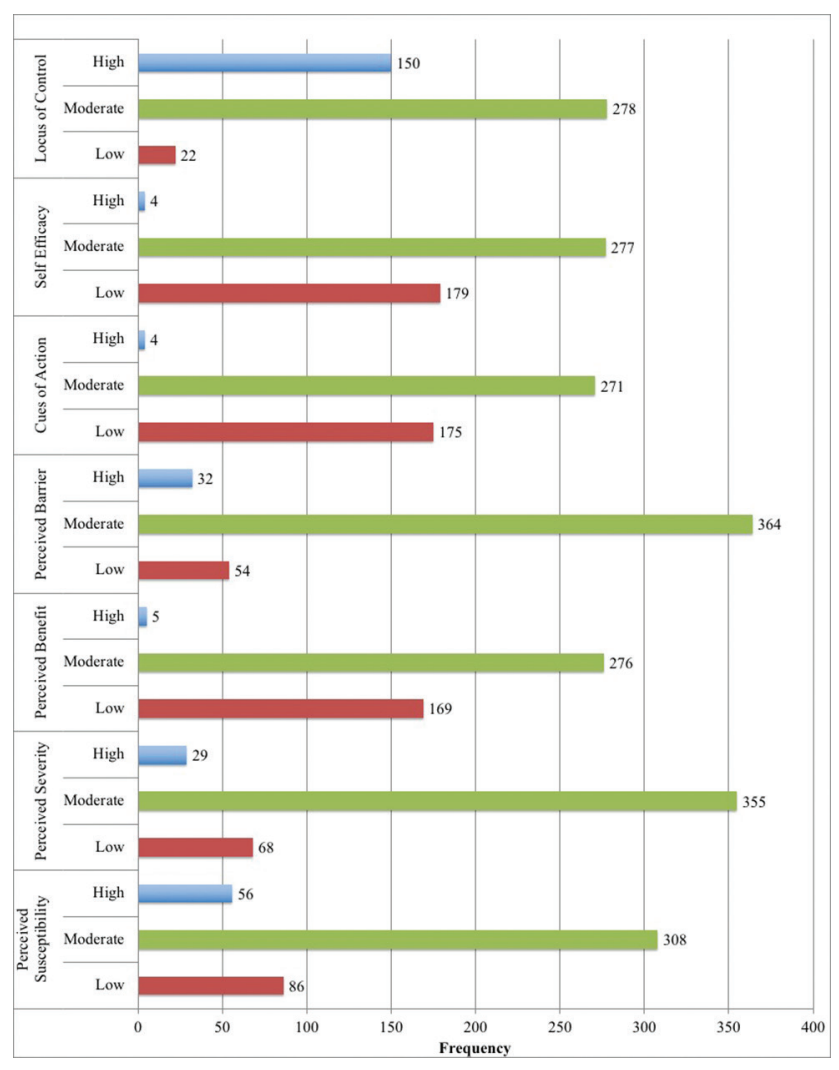

Fig. 1 Distribution of categorical score of total per dimension.
In the structural model that has been declared fit above, it appears that the path coefficient empirically has a $t$-value of $>1.96$, which is 2.41 . This means that the structural model of the direct relationship between parents' DBs and parents' perceptions about the formation of DF in preschool age children in the city of Bandung, proved to be significantly fit.

As the building components of the structural model, the two constructs of latent variables are reflected by each

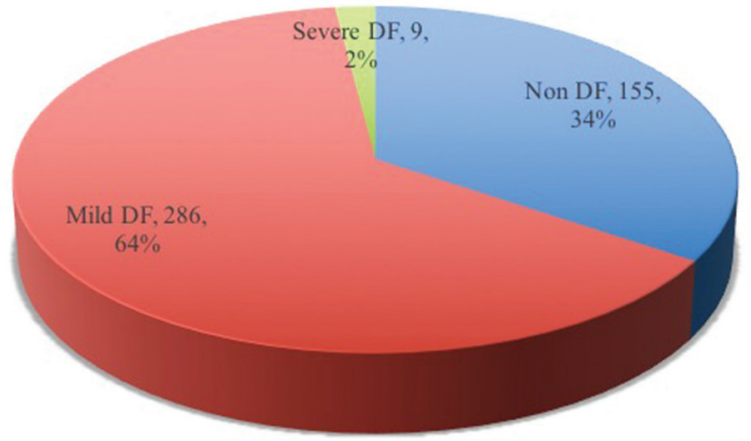

$\square$ Non DF $\square$ Mild DF $\sqcup$ Severe DF

Fig. 2 Distribution of parents' perception score categories regarding children's dental fear.

Table 1 SEM analysis

\begin{tabular}{|c|c|c|c|c|c|}
\hline \multicolumn{3}{|c|}{ Indicator } & \multicolumn{2}{|c|}{ t-Value } & \\
\hline \multicolumn{3}{|c|}{ Dental belief } & & & \\
\hline \multicolumn{3}{|c|}{ Perceived susceptibility } & \multicolumn{2}{|l|}{2.98} & \\
\hline \multicolumn{3}{|c|}{ Perceived severity } & \multicolumn{2}{|l|}{4.67} & \\
\hline \multicolumn{3}{|c|}{ Perceived benefit } & \multicolumn{2}{|l|}{4.90} & \\
\hline \multicolumn{3}{|c|}{ Perceived barrier } & \multicolumn{2}{|l|}{4.67} & \\
\hline \multicolumn{3}{|c|}{ Cues of action } & \multicolumn{2}{|l|}{5.13} & \\
\hline \multicolumn{3}{|c|}{ Self-efficacy } & \multicolumn{2}{|l|}{5.17} & \\
\hline \multicolumn{3}{|c|}{ Locus of control } & \multicolumn{2}{|l|}{-1.17} & \\
\hline \multicolumn{3}{|c|}{ Dental fear } & \multicolumn{2}{|l|}{+2} & \\
\hline \multicolumn{3}{|c|}{ Invasive treatment } & \multicolumn{2}{|l|}{4.65} & \\
\hline \multicolumn{3}{|c|}{ Health professional } & \multicolumn{2}{|l|}{7.68} & \\
\hline \multicolumn{3}{|c|}{ In relation with hospital } & \multicolumn{2}{|l|}{7.10} & \\
\hline \multicolumn{3}{|c|}{ In relation with stranger } & \multicolumn{2}{|l|}{5.10} & \\
\hline$\chi^{2} / \mathrm{df}$ & $p$-Value & Chi-square $\left(\chi^{2}\right)$ & RMSEA & GFI $>0.9$ & $\mathrm{CFI}>0.9$ \\
\hline $59.86 / 25$ & 0.00011 & 59.86 & 0.056 & 0.98 & 0.99 \\
\hline
\end{tabular}

Abbreviations: CFI, comparative fit index; df, degrees of freedom; GFI, goodness-of-fit index; RMSEA, root mean square error of approximation; SEM, structural equation modeling. 
indicator with a $t$-value of $>1.96$. Only the locus of control indicator has a $t$-value of 1.17 . This means that in the DB and DF measurement model, only confirmatory factor analysis per unit of locus of control are not significantly fit.

Judging from the loading factor of each indicator, 8 of the 11 indicators have a loading factor of $>0.50$, which means that all 8 indicators are valid at the very significant direction. Each of them is five of the seven DB indicators and three of the four DF indicators.

Survey results indicate that the direct effect structural model of parental DB significantly fit the formation of DF among children in Bandung City. The two scale models and their variable constructs are also fit, valid, and significant. The model testing yielded a diagram path based on the estimated model parameters, which can explain the structural relational model. The hypothesis testing based on the causal relation in the SEM is basically a test of path coefficient or $\beta$-coefficient One-directional $t$-value testing was done at a significance level of $\alpha=0.05$. Thus, null hypothesis would be rejected if it yielded a $t$-value of $>1.96$, which would then prove the hypothesis.

The independent and dependent variables had a low correlation value of $14 \%\left(R^{2}=0.14\right)$. The $\mathrm{R}^{2}$ value obtained from the structural regressional model in the SEM was corrected at an error effect of 0.86 (86\%). The error value resulting from measurement error, subjects' demographic differences, and other variables was not explored.

Seen from the perspective of structural modeling process, no previous study has examined the correlation between the variables tested. Generally, a test of an empirical model should refer to a specific model. This research, however, has resulted in an empirical model that can be referred to as a baseline for related future studies.

Thus, with HBM as its framework, the research found three correlated aspects related to the formation of DF in children. First, a significant correlation was found in general between parents' perception of susceptibility concerning the formation of DF in their children. Parents with low perception of risk factor would likely not be aware of what factors could cause DF. As a result, such parents would likely show lack of or even no effort to prevent DF.

The overall DB showed a significant correlation $(t$-value $=2.41)$ with the formation of DF in children. DF itself could be broken down into four aspects based on empirical findings. As - Fig. 3 shows, these four aspects can significantly account for DF with a $t$-value between 4.65 and 7.68.

\section{Discussion}

To develop effective behavior-changing health intervention, thorough research is needed to examine people's attitude, opinion, and knowledge, as reflected in the overall belief in the behavior needed. Several researches have focused on DB in the context of preventing certain behaviors. One research, for example, studied the correlation between DB and tooth-brushing behavior in dental caries prevention. ${ }^{17}$ Despite the conviction that application of theory can improve intervention efficacy, ${ }^{18}$ current interventions are generally not based on sound theoretical grounds or psychological models. ${ }^{19}$ No research has explored DB in the context of DF prevention. It is for this reason that in this research correlation between parental DB and the formation of DF in their preschool children was emphasized.

The model of parental belief in the research was modified from the preventive health behavior model called $\mathrm{HBM},{ }^{20}$ a predictive model based on the value expectancy theory as reflected in how threat and evaluation of behavior are perceived. Perception of threat consists of two key beliefs, namely susceptibility and severity concerning the formation of a certain behavior or health situation, in this case DF in children. Behavior analysis promotes health behavior and helps reduce performance barriers. Other aspects, including demographic characteristics, act as behavior-modifying factors for they affect motivation and perception. ${ }^{21}$

Little attention has been given to HBM in dentistry. Supporting data, however, have been suggested by a few studies. ${ }^{22,23}$ Better validated decision-making models, such as Theory of Planned Behavior ${ }^{24}$ and Protection Motivation Theory, ${ }^{25}$ have been applied to interventions of health behavior, including particularly fear. Yet, HBM was chosen for this research because of its concern with the much-debated issue of perception of risk concerning children with DF. HMB can approach this issue from the dimensions of perceived susceptibility and severity.

Using only parental report method to assess DF poses a problem of accuracy. Yet, applying Dental Fear Scale (DFS) to preschool children is not recommended because at this developmental stage, children generally still use symbol to represent their perception. An additional qualitative survey is thus needed to support parents' responses to DFS items.

Besides the quantitative data above, respondents' characteristic can also have indirect correlation with the object studied. Parental demographic factors (age, race, ethnicity), education, and socioeconomic conditions in HBM are some demographic variables that contribute to behavior modification and affect one's perception and tendency to act. ${ }^{20}$ In this research, the age of the parents chosen as respondents ranged from 23 to 48 years. They were categorized into two age groups, namely young adults and middle-aged. Most respondents belonged to the first group.

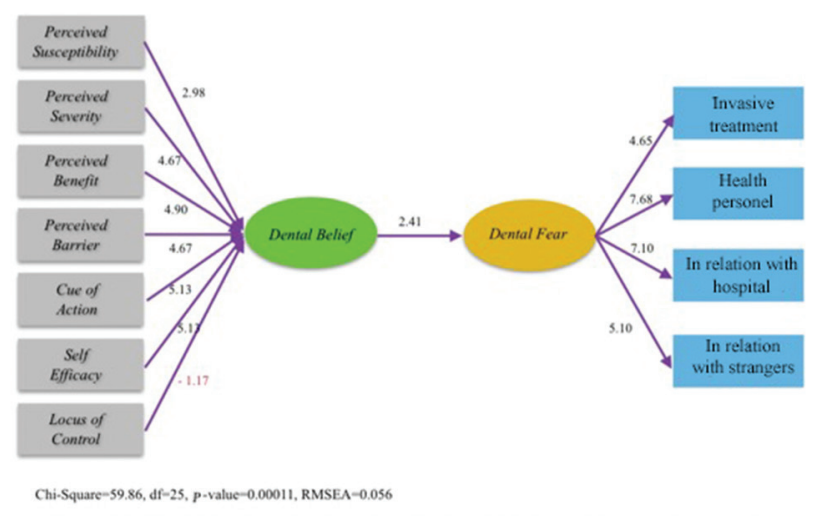

Fig. 3 Empirical model of dental belief relationships with parent perception of dental fear of their preschool child. 
Early adulthood is a period when one's role, for example, as a parent, becomes more established in his/her life pattern. A young adult's emotional, social, and moral development is closely related to the changes occurring in the preceding adolescent period. The period can also sometimes be marked with the presence of a sense of social crisis resulting from pressures from work and family. Parenting is to a great extent affected by one's development during the entire early adulthood. ${ }^{26}$

The extent to which parental DB contributes to the formation of DF in children was measured by using the DBS, which had been adapted from the HBM and Social Cognitive Theory. DBS measures seven dimensions. The higher the total score for each dimension, the more positive a respondent's belief in that dimension. In six categories, responses based on the results of the survey, scores in general ranged within the moderate category, except for the locus of control category. In this category, parents' scores were mostly high.

The dimensions in DBS represent several elements of beliefs, such as belief-forming experiences, are expressed in the perceived susceptibility and perceived barrier dimensions. The university background of most respondents enabled them to express their past dental treatment experiences when answering items in the perceived susceptibility and perceived barrier dimensions. Respondents with negative experiences scored low in the two categories and vice versa.

Though affected by many factors, beliefs, also expressed through behavior, varied among different people. Modifying factors such as age, education, and socioeconomic status affect DB and can lead to certain actions that contribute to the formation of DF in children.

DF in children was measured based on parents' self-report of what they perceive about their children's fear. DFS was adapted from the Indonesian transadaptation of the CFSS-DS. In terms of its construct, the DFS is not.

In terms its structure, DSF does not consist of several aspects. However, empirical results indicate that by means of factor analysis DFS is divisible into four factors. These four factors are then called aspects, namely invasive care, health personnel, hospital/clinic environment, and strangers.

This research found that children's DFS total score varied from 15 to 63, thus ranging from non-DF to severe DF. Parents' perception of children's DF mostly fell into the light DF category ( $n=286 ; 63.5 \%$ ). In general, DF measurement based on parental report frequently results in lower categories. This is caused by parents' failure to provide answers that accurately represent their children's fear. ${ }^{8}$ In such a case, it is recommended to use another measurement method to support findings. A physiological approach involving measuring children's pulse can be used. This, however, must be done in a supportive setting, namely positive clinic/hospital environment. ${ }^{27}$ As the research chose school as its setting, supporting measurement could not be done. This was redressed by involving a qualitative element, which shall be discussed separately. The limitations of the study are on the subject of parents who are only limited to the mother, does not measure the father's DB. For further research consideration, the father must be included as other variable.

\section{Conclusion}

Parental perception and behavior correlate with the formation of DF in preschool children. Measured by means of DBS, parental perception correlates in a fit model with the formation of DF in preschool children.

\section{Conflict of Interest}

None declared.

\section{References}

1 Nicolas E, Bessadet M, Collado V, Carrasco P, Rogerleroi V, Hennequin M. Factors affecting dental fear in French children aged 5-12 years. Int J Paediatr Dent 2010;20(5):366-373

2 Carter AE, Carter G, Boschen M, AlShwaimi E, George R. Pathways of fear and anxiety in dentistry: a review. World J Clin Cases 2014;2(11):642-653

3 Appukuttan D. Strategies to manage patients with dental anxiety and dental phobia: literature review. CCIDE; 2016 March:35-16

4 Buldur B, Armfield JM. Development of the Turkish version of the Index of Dental Anxiety and Fear (IDAF-4C+): dental anxiety and concomitant factors in pediatric dental patients. J Clin Pediatr Dent 2018;42(4):279-286

5 Setiawan AS, Agustiani H, Kendhawati L. Qualitative study on parental behavior as the source of dental fear development as reported by preschool students in Bandung. Eur J Dent 2018;12(4):480-484

6 Wu L, Gao X. Children's dental fear and anxiety: exploring family related factors. BMC Oral Health 2018;18(1):100

7 Hulley SB, Cummings SR, Browner WS, Grady DG, Newman TB, Designing Clinical Research. 4 ed. Philadelphia: Lippincott Williams \& Wilkins; 2013:1

8 Krikken JB, van Wijk AJ, ten Cate JM, Veerkamp JS. Measuring dental fear using the CFSS-DS. Do children and parents agree? Int J Paediatr Dent 2013;23(2):94-100

9 Beena JP. Dental subscale of children's fear survey schedule and dental caries prevalence. Eur J Dent 2013;7(2):181-185

10 Setiawan AS, Amriwijaya J, Fitriana E. Transadapted, reliability, and validity of children fear survey schedule-dental subscale in Bahasa Indonesia. Dent J 2015;48(1):1-6

11 Skinner CS, Tiro J, Champion VL, The Health Belief Model. In: Health Behavior Theory, Research, and Practice. Pennsylvania: Jossey-Bass;2015:75-80

12 Schwarzer R, Self-Efficacy, Thought Control of Action. London: Routledge; 2014:637

13 Setiawan AS, Purwono U, Development of Parental Dental Belief Scale on Child's Dental Fear. Medan IDGAI; 2015:1-7

14 Creswell JW, Research Design. 2nd ed. Los Angeles: Sage Publication Inc; 2003:262 p

15 Yoshikawa H, Weisner TS, Kalil A, Way N. Mixing qualitative and quantitative research in developmental science: uses and methodological choices. Dev Psychol 2008;44(2):344-354

16 Hair JF, Multivariate Data Analysis: A Global Perspective. Harlow: Pearson Education; 2010

17 Anagnostopoulos F, Buchanan H, Frousiounioti S, Niakas D, Potamianos G. Self-efficacy and oral hygiene beliefs about toothbrushing in dental patients: a model-guided study. Behav Med 2011;37(4):132-139

18 Brug J, Oenema A, Ferreira I. Theory, evidence and intervention mapping to improve behavior nutrition and physical activity interventions. Int J Behav Nutr Phys Act 2005;2(1):2

19 Brukiene V, Aleksejūniene J. An overview of oral health promotion in adolescents. Int J Paediatr Dent 2009;19 (3):163-171 
20 Rosenstock IM, Strecher VJ, Becker MH. Social learning theory and the Health Belief Model. Health Educ Q 1988;15(2):175-183

21 Riekert KA, Ockene JK, Pbert, P. The Handbook of Health Behavior Change. 4th ed. New York: Springer Publishing Company; 2013

22 Riekert KA, Ockene JK, Pbert L. Testing the Health Belief Model: LISREL analysis of alternative models of causal relationships between health beliefs and preventive dental behavior. Social Psychology Quarterly. US. American Sociological Assn 1986;49(1):45-60

23 Tan BS, Ng KH, Esa R. Health beliefs in oral cancer: Malaysian estate Indian scenario. Patient Educ Couns 2001;42(3):205-211
24 Ajzen I. The theory of planned behavior. Organ Behav Hum Decis Process 1991;50(2):179-211

25 Rogers R, Cognitive and physiological processes in fear based attitude change: a revised theory of protection motivation. In: Cacioppo J, Petty R, eds. Social Psychophysiology: A Sourcebook. New York: The Guildford Press; 2014 153-176

26 Santrock JW, Life-Span Development. New York: McGraw-Hill; 2013

27 Nakai Y, Hirakawa T, Milgrom P, et al. The Children's Fear Survey Schedule-Dental Subscale in Japan. Community Dent Oral Epidemiol 2005;33(3):196-204 